\title{
Hyperbaric Oxygen Therapy to Treat Acute Sport-Related Traumatic Brain Injuries: A Case Series
}

\author{
Patricia R. Roby, PhD, ATC, ${ }^{1}$ Robert C. Lynall, PhD, ATC, ${ }^{2}$ Michael J. Cools, MD, ${ }^{1}$ \\ Stephen W. Marshall, PhD, ${ }^{1}$ Janna C. Fonseca, MEd, ATC ${ }^{3}$ James R. Stevens, MD, ${ }^{3}$ \\ and Jason P. Mihalik, PhD, CAT(C), ATC, FACSM, FNATA ${ }^{1}$ \\ ${ }^{1}$ The University of North Carolina at Chapel Hill; ${ }^{2}$ University of Georgia; ${ }^{3}$ Carolina Family Practice \& Sports Medicine
}

\begin{abstract}
We report on hyperbaric oxygen $\left(\mathrm{HBO}_{2}\right)$ therapy used to improve postinjury outcomes in eight acutely concussed high school student-athletes ( 5 males, 3 females, mean age $=16.0 \pm 1.2$ years). Patients were randomly assigned into one of three intervention groups: (a) $\mathrm{HBO}_{2}$ therapy; (b) hyperbaric therapy with compressed medical-grade air (HBA); or (c) normobaric $100 \% \mathrm{O}_{2}$ therapy. All patients completed five 1-hr treatments within the first 10 days following his or her concussion. Main outcome measures included mental status examination, symptom burden, and the number of days from injury until the physician permitted the student-athlete to return to activity. Patients receiving $\mathrm{HBO}_{2}$ treatment experienced the greatest absolute symptom reduction over the five treatment sessions. No meaningful differences were found in mental status examination. All participants returned to activity in a similar timeframe. $\mathrm{HBO}_{2}$ therapy may be an effective option for the acute treatment of postconcussion symptoms, particularly in young athletes presenting with a high symptom burden.
\end{abstract}

Keywords: adolescent, concussion, symptoms

Student-athletes typically experience deficits in neurocognitive function, motor control, and an array of clinical symptoms following concussion. ${ }^{1}$ Insult to the neural tissue causes changes in cellular and physiological function resulting in a loss of energy stores coupled with decreased cerebral blood flow. ${ }^{2}$ The re-

\section{Key Points}

Consensus statements have

recently moved away from strict rest following concussion.

Treatments aimed at reducing initial symptom burden may reduce recovery times.

Hyperbaric oxygen therapy may be an effective treatment in high school athletes.

sulting mismatch between supply and demand results in a potentially damaging energy crisis, which has been associated with migraine-like symptoms, headaches, dizziness, photophobia, phonophobia, and nausea. ${ }^{2}$ Elevated symptom endorsement ${ }^{3}$ and greater symptom severity ${ }^{4}$ at the time of injury (i.e., symptom burden) have been associated with prolonged recovery following concussion. Clinicians could plausibly improve recovery times by addressing this initial symptom burden. Consensus statements have only recently deviated from longtime recommendations encouraging rest until

Roby and Mihalik are with the Department of Exercise and Sport Science, Matthew Gfeller Sport-Related Traumatic Brain Injury Research Center, The University of North Carolina at Chapel Hill, Chapel Hill, NC, USA; and Human Movement Science Curriculum, Department of Allied Health Sciences, The University of North Carolina at Chapel Hill, Chapel Hill, NC, USA. Lynall is with UGA Concussion Research Laboratory, Department of Kinesiology, University of Georgia, Athens, GA, USA. Cools and Mihalik are with the Department of Neurosurgery, The University of North Carolina at Chapel Hill, Chapel Hill, NC, USA. Marshall is with the Injury Prevention Research Center, The University of North Carolina at Chapel Hill, Chapel Hill, NC, USA. Fonseca and Stevens are with Carolina Family Practice \& Sports Medicine, Raleigh, NC, USA. Mihalik (jmihalik@email.unc.edu) is corresponding author. symptom resolution. Thus, there are limited data demonstrating the concussion treatments that will benefit young athletes the most.

Using hyperbaric oxygen $\left(\mathrm{HBO}_{2}\right)$ therapy as a medical treatment to support and accelerate the body's own healing mechanisms to speed recovery from injury, surgery, or chronic illness has been well established. ${ }^{5-9}$ Using $\mathrm{HBO}_{2}$ therapy has demonstrated benefits in animal studies, ${ }^{10}$ as well as those suffering from moderate to severe traumatic brain injury. ${ }^{11}$ Unfortunately, it has not been adequately studied as an acute concussion treatment. Giza and Hovda ${ }^{2}$ previously described the neurometabolic cascade resulting from concussion. During the days immediately following head trauma, cerebral blood flow (which carries oxygen required by tissues to survive and repair) may be reduced to $50 \%$ of normal. ${ }^{12,13}$ Using $\mathrm{HBO}_{2}$ therapy may mitigate the reduced cerebral blood flow observed following concussion by supersaturating the tissues with oxygen. In this case series, we describe the effect of $\mathrm{HBO}_{2}$ therapy on reducing initial symptom burden in acutely concussed high school student-athletes compared to two different placebo treatments: (a) $100 \% \mathrm{O}_{2}$ normobaric therapy and (b) hyperbaric therapy with medical-grade air.

\section{Case Series}

\section{Patients}

This case series presents eight cases: three randomly assigned to hyperbaric therapy with $100 \%$ oxygen $\left(\mathrm{HBO}_{2}\right)$, three randomly assigned to hyperbaric therapy with medical-grade air (HBA), and two randomly assigned to $100 \% \mathrm{O}_{2}$ normobaric therapy. The patients 
included in this case series were referred to a community-based family practice facility by his or her school's athletic trainer if they experienced signs and symptoms consistent with concussion. Once referred, a systematic and protocolled concussion evaluation was performed. Every physician rendering a concussion diagnosis was board-certified in family medicine and had completed a sports medicine fellowship. They were all experienced in evaluating and managing sport-related concussion. Once a student-athlete was diagnosed with concussion, the study protocol and objectives were discussed with the patient and their legal guardian. After eligibility was confirmed (see Table 1 for exclusion criteria), legal guardians provided informed consent and participants provided minor assent on forms approved by the Office of Human Research Ethics at the University of North Carolina at Chapel Hill.

\section{Examination}

We employed the Postconcussion Symptom Scale (PCSS) and Standardized Assessment of Concussion (SAC) to measure symptoms and mental status, respectively. The PCSS checklist is a selfreported symptom assessment that measures the presence and severity of 22 symptoms. Symptoms are scored on a 7-point Likert scale ranging from 0 (no symptom) to 6 (severe symptom) (Table 2). ${ }^{14,15}$ The SAC was designed to be a brief sideline concussion assessment and is sensitive and specific to even the mildest concussion in the absence of observable injury signs. ${ }^{16-20}$ These outcomes were measured at initial visit and each follow-up visit during the recovery process until such time that the physician permitted the student-athlete to return to activity. Our main outcomes also included the number of days from injury until cleared for activity, which was defined as the day a physician cleared an athlete to return to team workouts and regularly scheduled team practices. We selected return to activity as the endpoint because this represents a readily documented clinical decision, and we were concerned that day of return to full contact may be harder to document in our community sports teams.

\section{Intervention}

Following consent, participants were randomly assigned and blinded to a treatment group. Cards with random treatment group assignments were created, and participants were sequentially assigned as they enrolled in the study. Group assignment was not shared with the participants or his/her treating physicians. Additionally, our participants did not obtain nor were they prescribed any concurrent treatments during the initial 10 days of their injury management. The three treatment groups were as follows: (a) $\mathrm{HBO}_{2}$ therapy (treatment at 1.5 atmospheres, $100 \% \mathrm{O}_{2}$ at pressure equal to $15 \mathrm{ft}$ below sea level); (b) hyperbaric therapy with medical-grade air (HBA; treatment at 1.5 atmospheres, medical grade air); and (c) $100 \% \mathrm{O}_{2}$ therapy with negligible pressure. Due to the same relative pressures for $\mathrm{HBO}_{2}$ and $\mathrm{HBA}$, participants were unable to tell the difference and thus blinded to the treatment arm they were randomly assigned. Negligible pressure in the $\mathrm{O}_{2}$ therapy group was provided by increasing the pressure inside the chamber until the participant reported feeling their ears "pop"; those pressures were not high enough to affect oxygen diffusion. The participant received the feeling of pressure being applied and thus was blinded to the treatment arm. The intervention was administered in a facility independent of the primary care clinic. All participants and all members of the medical care teams were blinded to treatment group. All patients received five 1-hr sessions within 10 days of sustaining his or her concussion with no more than 1 day between any two treatments regardless of treatment arm.

Prior to each treatment session, all participants completed the PCSS. Participants completed the SAC and repeated the PCSS immediately after each treatment session. Regardless of treatment arm, patients were placed in a SIGMA 40 Monoplace Hyperbaric System (Perry Baromedical Corporation, Riviera Beach, FL) equipped with a safety interlock system and monitored by a Certified Hyperbaric Technician. The monoplace chamber for all patients is pressurized with $100 \%$ oxygen. All patients wore a non-rebreather mask, which allowed air to be delivered directly to the patient, while

\section{Table 2 Postconcussion Symptom Scale (PCSS) Symptoms}

\begin{tabular}{ll}
\hline Symptoms & \\
\hline Headache & Sensitivity to light \\
Nausea & Sensitivity to noise \\
Emesis & Increased sadness \\
Balance problems & Nervousness \\
Dizziness & Feeling more emotional \\
Fatigue & Numbness or tingling \\
Trouble falling asleep & Feeling slowed down \\
Sleeping more than usual & Sensation of being "in a fog" \\
Sleeping less than usual & Difficulty with concentration \\
Drowsiness & Difficulty with memory \\
Irritability & Visual problems \\
\hline
\end{tabular}

\section{Table 1 Exclusion Criteria}

\begin{tabular}{l}
\hline Criteria \\
\hline Loss of consciousness for $>20$ min at time of injury \\
Glasgow Coma Scale $\leq 13$ at time of injury \\
Evidence of drug use \\
Concurrent injury (e.g., fractures, sprains, etc.) \\
Current hospitalization \\
*History of nitrogen dioxide poisoning, emphysema, shock, lung disease/disorder, and pneumothorax \\
History of attention deficit disorders and learning disabilities \\
$*$ Claustrophobia
\end{tabular}

*These exclusion criteria were specific to employing the hyperbaric oxygen chambers. 
preventing the patient from breathing the air/gases used to pressurize the monoplace chamber. The monoplace chamber was compressed with $100 \%$ oxygen to a pressure of 1.5 atmospheres at a rate of $1 \mathrm{psi} /$ min. Treatments lasted $60 \mathrm{~min}$ at 1.5 atmospheres, followed by decompression of the chamber at a rate of $1 \mathrm{psi} / \mathrm{min}$.

\section{Comparative Outcomes}

Eight patients ( 3 females, 5 males, mean age $=16.0 \pm 1.2$ years) and their legal guardians consented to participate in this study (Table 3). No adverse events were noted for any patient. The most common sport played was soccer (4/8), with the remaining athletes sustaining a concussion while competing in baseball, cheer, lacrosse, or volleyball. We computed clinically relevant descriptive data and present them in our case series results and the associated tables and figures. Given we present a case series without the sample size expected of a traditional scientific study, we were unable to perform formal statistical comparisons between the treatment arms. Total SAC score remained consistent throughout the five testing sessions for all treatments (Figure 1).

$\mathrm{HBO}_{2}$ Therapy. Overall, the participants receiving $\mathrm{HBO}_{2}$ therapy returned to activity in an average of $13.7 \pm 5.1$ days (median $=$ 15 days, range $=8-18$ days). Following five 1-hr treatment sessions, patient 3 experienced a total symptom score reduction of 37 points (initial score $=41$; final score $=4,90.2 \%$ reduction), patient 6 experienced a total symptom score reduction of 7 points (initial score $=9$, final score $=2,77.8 \%$ reduction), and patient 7 experience a total symptom score reduction of 72 (initial score $=$ 77 , final score $=5,93.5 \%$ reduction).

HBA Therapy. Average time to return to activity for the participants receiving HBA therapy was $13.0 \pm 5.7$ days $($ median $=$ 13 days; range $=9-17$ days). Following five 1-hr treatment sessions, patient 2 experienced a 14-point reduction in total symptom score (initial score $=16$, final score $=2,87.5 \%$ reduction) and patient 5 experienced a 30 -point reduction in total symptom score (initial score $=37$, final score $=7,81.1 \%$ reduction).

$\mathrm{O}_{2}$ Therapy. Patients receiving $\mathrm{O}_{2}$ therapy returned to activity in an average of $19.0 \pm 16.5$ days (median $=11$ days, range $=$ 8-38 days). Following five $1 \mathrm{hr}$ treatment sessions, patient 1 experienced a 20-point reduction in total symptom score (initial score $=24$, final score $=4,83.3 \%$ reduction) and patient 8 experienced a 22-point reduction in total symptom score (initial score $=23$, final score $=1,95.7 \%$ reduction). Patient 4 did not report for their final treatment session but experienced a 41-point reduction in total symptom score following four 1-hr

Table 3 Demographic Information and Patient Histories

\begin{tabular}{|c|c|c|c|c|c|c|c|c|}
\hline Patient & Group $^{a}$ & $\begin{array}{c}\text { Age } \\
\text { (years) }\end{array}$ & Sex & Sport & $\begin{array}{l}\text { \# of Previous } \\
\text { Concussions }\end{array}$ & $\begin{array}{l}\text { Days Between Injury } \\
\text { and First Treatment }\end{array}$ & $\begin{array}{l}\text { Days Until } \\
\text { Cleared for } \\
\text { Activity }\end{array}$ & $\begin{array}{l}\text { Symptom Score } \\
\text { Reduction }^{\text {b }}\end{array}$ \\
\hline 1 & $\mathrm{O}_{2}$ & 17 & $\mathrm{~F}$ & Soccer & 4 & 3 & 11 & 20 \\
\hline 2 & HBA & 15 & F & Volleyball & 0 & 3 & 17 & 14 \\
\hline 3 & $\mathrm{HBO}_{2}$ & 17 & M & Lacrosse & 1 & 3 & 15 & 37 \\
\hline 4 & $\mathrm{O}_{2}$ & 18 & M & Soccer & 0 & 3 & 8 & $41^{\mathrm{c}}$ \\
\hline 5 & $\mathrm{HBA}$ & 15 & M & Soccer & 0 & 4 & 9 & 30 \\
\hline 6 & $\mathrm{HBO}_{2}$ & 16 & M & Soccer & 1 & 2 & 8 & 7 \\
\hline 7 & $\mathrm{HBO}_{2}$ & 15 & M & Baseball & 0 & 4 & 18 & 72 \\
\hline 8 & $\mathrm{O}_{2}$ & 15 & F & Cheer & 0 & 4 & 38 & 22 \\
\hline
\end{tabular}

${ }^{a}$ Group assignment identified as follows: (a) $\mathrm{O}_{2}$ : treatment group received $100 \%$ oxygen at normobaric pressure; (b) HBA: treatment group received medical-grade air at 1.5 atmospheric pressure; and (c) $\mathrm{HBO}_{2}$ : treatment group received $100 \%$ oxygen at 1.5 atmospheric pressure. ${ }^{\mathrm{b}}$ Symptom score reduction represents the improvement (positive values represent decreased burden) measured after completing the fifth therapy session relative to their initial score. ${ }^{\mathrm{c}}$ Patient 4 did not report for their final treatment session; reduction follows four treatment sessions.
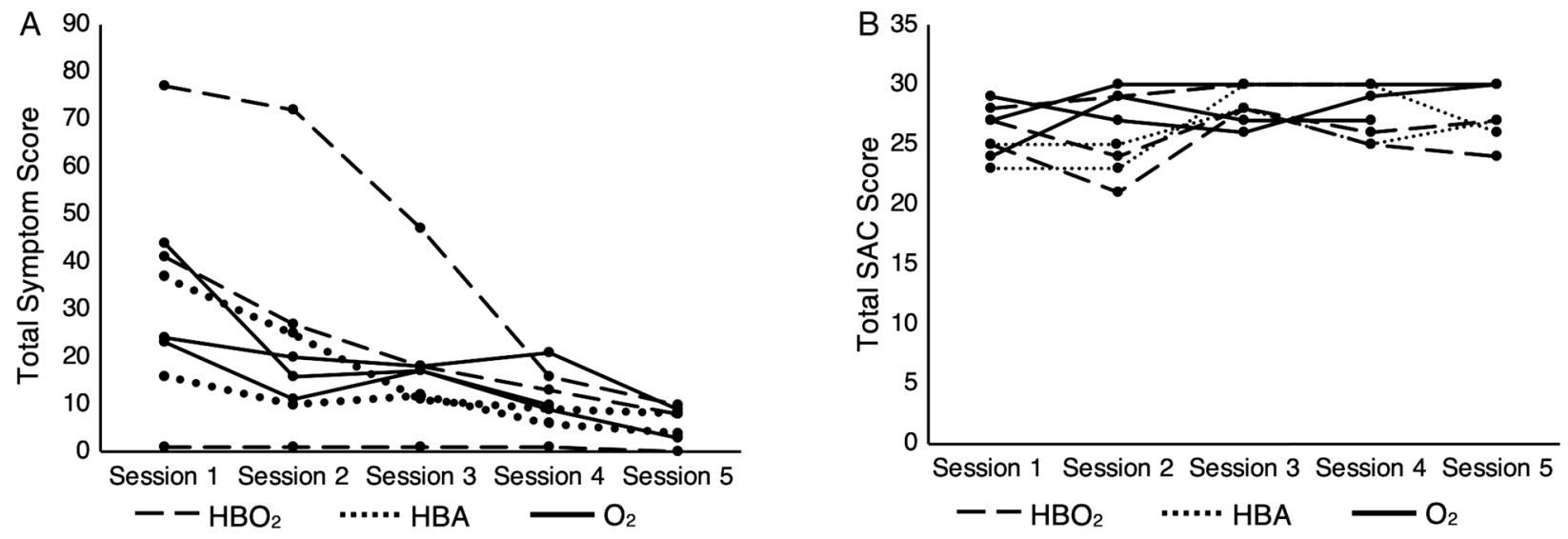

Figure 1 - Change in clinical outcomes. Total symptom score (A) and total Standardized Assessment of Concussion (SAC) score (B) for each patient following five treatment sessions. $\mathrm{HBO}_{2}=$ hyperbaric oxygen therapy; $\mathrm{HBA}=1.5$ atmospheres of pressure with medical grade air; $\mathrm{O}_{2}=100 \%$ oxygen . 
treatment sessions (initial score $=44$, final score $=3,93.1 \%$ reduction).

\section{Discussion}

We performed this study to determine if $\mathrm{HBO}_{2}$ therapy could be an effective treatment for acute concussion in high school studentathletes. Though all patients experienced similar reductions in total symptom severity score, patients receiving $\mathrm{HBO}_{2}$ experienced the greatest absolute change in total symptom score following five 1-hr treatments. Additionally, some (but not all) patients receiving $\mathrm{HBO}_{2}$ therapy also saw the greatest pre- to posttreatment improvements in symptom scores within each therapy session.

Our results suggest that $\mathrm{HBO}_{2}$ therapy may be an effective treatment to address initial symptom burden for high school student-athletes suffering from concussion. Of those receiving $\mathrm{HBO}_{2}$ treatment, patient 7 (initial symptom score =77) was markedly more symptomatic at the beginning of the trial relative to those receiving $\mathrm{HBA}$ or $\mathrm{O}_{2}$ yet recovered to the same degree as the other patients by the fifth treatment. Patient 3 reported a greater initial total symptom score than average ${ }^{21}$ and recovered in a similar time to participants receiving other treatment. Initial symptom burden has been associated with prolonged or complex recoveries following concussion. ${ }^{3,4,22} \mathrm{McCrea}$ et al. ${ }^{3}$ found athletes reporting total symptom severity scores $>20$ from baseline on immediate testing, 2-3 hr postinjury, and 1 day postinjury had $2.56,2.89$, and 4.14 times greater risk of prolonged recovery, respectively. By actively addressing initial symptom burden, $\mathrm{HBO}_{2}$ therapy may be effective in reducing the risk of prolonged or complicated recovery.

Additionally, we found no meaningful changes in SAC total scores. The average score for each patient at initial evaluation was similar to normative values suggesting either that the participants did not report postinjury deficits in mental status or that the participants' mental status had recovered by the time SAC was administered. From initial evaluation to the fifth treatment session, SAC total scores remained within 1 standard deviation of normative values for this age group, ${ }^{23}$ suggesting hyperbaric or normobaric oxygen therapy does not negatively affect mental status as measured by the SAC.

We caution that our data supporting $\mathrm{HBO}_{2}$ therapy as an acute concussion treatment require substantial follow-up studies to support efficacy. Off-label $\mathrm{HBO}_{2}$ treatments may cost as much as $\$ 300-400$ for a $90-$ min treatment. ${ }^{24}$ Determining the optimum protocol for treating concussions will require studying considerably more patients employing the randomized-controlled trial designs we propose in this case series investigation.

\section{Clinical Bottom Line}

The standard of care for athletes suffering from sport-related concussion had long consisted of both physical and cognitive rest until their self-reported symptoms resolved and objective clinical measures of concussion show signs of recovery. This standard of care provides little to no active treatment options beyond a passive wait-and-see approach for which clinicians have very little evidence-based understanding. More recent guidelines $^{25}$ have softened this stance to permit symptom-limited activity during the first stage of the patient's return-to-sport strategy. Our understanding of innovative acute treatment options will continue to evolve with emerging science addressing these clinical challenges. This case series presents formative data suggesting that $\mathrm{HBO}_{2}$ therapy may be effective in reducing initial symptom burden in the acute stages following sport-related concussion in adolescent athletes. Future research should continue investigating acute interventions, such as $\mathrm{HBO}_{2}$ therapy, targeted at minimizing the risks of developing persistent complications related to concussion in young athletes.

\section{Acknowledgments}

This case series was funded by the National Operating Committee on Standards for Athletic Equipment (NOCSAE). The results of this case series do not constitute endorsement by the NOCSAE. The results of the case series are presented clearly, honestly, and without fabrication, falsification, or inappropriate data manipulation. The authors have no conflicts of interests to disclose related to this case series.

\section{References}

1. Broglio SP, Cantu RC, Gioia GA, et al. National Athletic Trainers' Association position statement: management of sport concussion. J Athl Train. 2014;49(2):245-265. PubMed ID: 24601910 doi:10. 4085/1062-6050-49.1.07

2. Giza CC, Hovda DA. The new neurometabolic cascade of concussion. Neurosurgery. 2014;75(suppl):S24-S33. doi:10.1227/NEU. 0000000000000505

3. McCrea M, Guskiewicz K, Randolph C, et al. Incidence, clinical course, and predictors of prolonged recovery time following sportrelated concussion in high school and college athletes. J Int Neuropsychol Soc. 2013;19(1):22-33. PubMed ID: 23058235 doi:10. 1017/S1355617712000872

4. Meehan WP, Mannix RC, Stracciolini A, Elbin RJ, Collins MW. Symptom severity predicts prolonged recovery after sport-related concussion, but age and amnesia do not. J Pediatr. 2013;163(3): 721-725. PubMed ID: 23628374 doi:10.1016/j.jpeds.2013.03.012

5. Hargens AR, Schmidt DA, Evans KL, et al. Quantitation in a model of skeletal- compartment necrosis syndrome. J Bone Joint Surg. 1981; 63(4):631-636. PubMed ID: 7217130 doi:10.2106/00004623198163040-00014

6. Pierce AK. Assisted respiration. Annu Rev Med. 1969;20(1):431-448. PubMed ID: 4893408 doi:10.1146/annurev.me.20.020169.002243

7. Bird AD, Telfer ABM. Effect of hyperbaric oxygen on limb circulation. Lancet. 1965;285(7381):355-356. doi:10.1016/S01406736(65)91783-6

8. Nylander G, Nordstrtim H, Eriksson E. Effects of hyperbaric oxygen on oedema formation after a scald burn. Burns. 1984;10(3):193-196. http://ac.els-cdn.com/0305417984900263/1-s2.0-0305417984900263main.pdf?_tid=ea6c6098-7d1c-11e7-88cf-00000aacb360\&acdnat $=150$ 2295060_8e322e278c41c998b522f5af014eae31. Accessed August 8, 2017. doi:10.1016/0305-4179(84)90026-3

9. Sukoff M, Ragatz RE. Hyperbaric oxygenation for the treatment of acute cerebral edema. Neurosurgery. 1982;10(1):29-38. PubMed ID: 7057975

10. Huang L, Obenaus A, Hamer M, Zhang JH. Neuroprotective effect of hyperbaric oxygen therapy in a juvenile rat model of repetitive mild traumatic brain injury. Med Gas Res. 2016;6(4):187-193. PubMed ID: 28217290 doi:10.4103/2045-9912.196900

11. Wang F, Wang Y, Sun T, Yu H-L. Hyperbaric oxygen therapy for the treatment of traumatic brain injury: a meta-analysis. Neurol Sci. 2016;37(5):693-701. PubMed ID: 26746238 doi:10.1007/s10072015-2460-2 
12. Yamakami I, McIntosh TK. Effects of traumatic brain injury on regional cerebral blood flow in rats as measured with radiolabeled microspheres. J Cereb Blood Flow Metab. 1989;9(1):117-124. PubMed ID: 2910893 doi:10.1038/jcbfm.1989.16

13. Yuan XQ, Prough DS, Smith TL, Dewitt DS. The effects of traumatic brain injury on regional cerebral blood flow in rats. J Neurotrauma. 1988;5(4):289-301. PubMed ID: 3249308 doi:10.1089/neu.1988.5.289

14. Broglio SP, Macciocchi SN, Ferrara MS. Sensitivity of the concussion assessment battery. Neurosurgery. 2007;60(6):1050-1058. PubMed ID: 17538379 doi:10.1227/01.NEU.0000255479.90999.C0

15. Patel AV, Mihalik JP, Notebaert AJ, Guskiewicz KM, Prentice WE. Neuropsychological performance, postural stability, and symptoms after dehydration. J Athl Train. 2007;42(1):66-75. PubMed ID: 17597946

16. McCrea M. Standardized mental status assessment of sports concussion. Clin J Sport Med. 2001;11(3):176-181. PubMed ID: 11495322 doi:10.1097/00042752-200107000-00008

17. McCrea M, Kelly JP, Randolph C, Cisler R, Berger L. Immediate neurocognitive effects of concussion. Neurosurgery. 2002;50(5): 1032-1040. PubMed ID: 11950406 doi:10.1097/00006123-20020 5000-00017

18. McCrea M, Kelly JP, Randolph C, et al. Standardized assessment of concussion (SAC): on-site mental status evaluation of the athlete. J Head Trauma Rehabil. 1998;13(2):27-35. PubMed ID: 9575254 doi:10.1097/00001199-199804000-00005

19. McCrea M, Kelly JP, Kluge J, Ackley B, Randolph C. Standardized assessment of concussion in football players. Neurology.
1997;48(3):586-588. PubMed ID: 9065531 doi:10.1212/WNL. 48.3.586

20. Barr WB, McCrea M. Sensitivity and specificity of standardized neurocognitive testing immediately following sports concussion. J Int Neuropsychol Soc. 2001;7(6):693-702. PubMed ID: 11575591 doi: $10.1017 /$ S1355617701766052

21. Meehan WP, Mannix R, Monuteaux MC, Stein CJ, Bachur RG. Early symptom burden predicts recovery after sport-related concussion. Neurology. 2014;83(24):2204-2210. PubMed ID: 25381296 doi:10. 1212/WNL.0000000000001073

22. Lau B, Lovell MR, Collins MW, Pardini J. Neurocognitive and symptom predictors of recovery in high school athletes. Clin J Sport Med. 2009;19(3):216-221. PubMed ID: 19423974 doi:10.1097/JSM. $0 \mathrm{~b} 013 \mathrm{e} 31819 \mathrm{~d} 6 \mathrm{edb}$

23. Valovich McLeod TC, Bay RC, Lam KC, Chhabra A. Representative baseline values on the Sport Concussion Assessment Tool 2 (SCAT2) in adolescent athletes vary by gender, grade, and concussion history. Am J Sports Med. 2012;40(4):927-933. doi:10.1177/03635465114 31573

24. Tibbles PM, Edelsberg JS. Hyperbaric-oxygen therapy. $N$ Engl J Med. 1996;334(25):1642-1648. PubMed ID: 8628361 doi:10.1056/ NEJM199606203342506

25. McCrory P, Meeuwisse W, Dvořák J, et al. Consensus statement on concussion in sport-the 5th international conference on concussion in sport held in Berlin, October 2016. Br J Sports Med. 2017; 51(11):838-847. PubMed ID: 28446457 doi:10.1136/bjsports2017-097699 